\title{
Prosthesis use in persons with lower- and upper-limb amputation
}

\author{
Katherine A. Raichle, PhD; ${ }^{1-2 *}$ Marisol A. Hanley, PhD $;^{2}$ Ivan Molton, PhD; ${ }^{2}$ Nancy J. Kadel, MD; ${ }^{3}$ Kellye \\ Campbell, MN, ARNP; ${ }^{2}$ Emily Phelps, BS; ${ }^{2}$ Dawn Ehde, PhD; ${ }^{2}$ Douglas G. Smith, MD $^{3}$ \\ ${ }^{1}$ Department of Psychology, Seattle University, Seattle, WA; Departments of ${ }^{2}$ Rehabilitation Medicine and \\ ${ }^{3}$ Orthopaedics and Sports Medicine, University of Washington School of Medicine, Seattle, WA
}

\begin{abstract}
This study identified clinical (e.g., etiology) and demographic factors related to prosthesis use in persons with upper- and lower-limb amputation (ULA and LLA, respectively) and the effect of phantom limb pain (PLP) and residual limb pain (RLP) on prosthesis use. A total of 752 respondents with LLA and 107 respondents with ULA completed surveys. Factors related to greater use (hours per day) for persons with LLA included younger age, full- or part-time employment, marriage, a distal amputation, an amputation of traumatic etiology, and an absence of PLP. Less use was associated with reports that prosthesis use worsened RLP, and greater prosthesis use was associated with reports that prosthesis use did not affect PLP. Having a proximal amputation and reporting lower average PLP were related to greater use in hours per day for persons with an ULA, while having a distal amputation and being married were associated with greater use in days per month. Finally, participants with LLA were significantly more likely to wear a prosthesis than those with ULA. These results underscore the importance of examining factors related to prosthesis use and the differential effect that these variables may have when the etiology and location of amputation are considered.
\end{abstract}

Key words: amputation, demographics, etiology, factors, limb, pain, phantom, prosthesis, prosthetic rehabilitation, residual, use.

\section{INTRODUCTION}

Each year in the United States, an estimated 158,000 persons undergo amputation, with the overall number of amputations being performed increasing [1]. Although limb loss can cause severe disturbance in locomotion and functional abilities, prosthetic rehabilitation has the potential to restore function and increase quality of life and is associated with a greater likelihood of returning to employment [2-3]. Despite these potential benefits, a substantial number of persons with amputations do not use a prosthesis. For example, documented rates of prosthesis use vary from 27 [4] to 56 percent [5] for upperlimb amputation (ULA) and from 49 [6] to 95 percent [7] for lower-limb amputation (LLA). A number of studies have attempted to identify variables that explain inconsistent use rates and identify persons less likely to wear and benefit from a prosthesis. Unfortunately, the existing literature is equivocal and limited by a number of factors.

Although some recent exceptions can be found [710], most prior research in prosthesis use has focused almost exclusively on persons with LLA secondary to vascular dysfunction, representing predominantly elderly persons [6,11-14]. Numerous alternative pathways to limb loss exist, including cancer, trauma, and infection, each of which may represent widely varying clinical circumstances and potentially different demographic characteristics.

Abbreviations: LLA = lower-limb amputation, NRS = numeric rating scale, $\mathrm{PLP}=$ phantom limb pain, RLP $=$ residual limb pain, $\mathrm{SD}=$ standard deviation, ULA = upper-limb amputation, VA = Department of Veterans Affairs.

* Address all correspondence to Katherine A. Raichle, PhD; Department of Psychology, Seattle University, 901 12th Ave, Seattle, WA 98122; 206-296-2815; fax: 206-296-2141. Email: raichlek@seattleu.edu

DOI: 10.1682/JRRD.2007.09.0151 
Moreover, ULAs pose markedly different challenges to functioning and have not yet received wide attention in the literature.

A second limitation of prior studies is the lack of clearly identified predictors of prosthesis use. Clinical and demographic factors associated with prosthesis use have included sex, age, education, level of amputation, cognitive impairment, satisfaction, education $[6,8,11,13,15-$ $18]$, and cosmesis for persons with ULA $[17,19]$. However, several inconsistencies are present in these studies. For example, in a sample of 414 persons with ULA, Burger and Marincek found that level of amputation, loss of dominant hand, and time between amputation and prosthesis fitting were all related to prosthesis use [17]. Alternatively, Roeschlein and Domholdt identified a number of other demographic factors related to use, including education, employment, acceptance of amputation, and perceptions of prosthesis expense, but failed to identify loss of dominant hand as an important factor [20]. These findings highlight the importance of broadening the focus of our attention to include other relevant clinical variables.

A third limitation of research in this area is that despite the relatively large number of persons with amputations who report phantom limb pain (PLP) and residual limb pain (RLP) [21-22], few studies examine the potential effect of pain on prosthesis use $[4,18,23]$. The data that do exist are equivocal. In one study of persons with ULA, Dudkiewicz and colleagues found that neither RLP nor PLP were related to prosthesis use [23]. Alternatively, Wright and colleagues failed to find a relationship between PLP and prosthesis use for persons with ULA but did find that the absence of RLP was related to increased prosthesis use [4]. To our knowledge, only one study has considered the effect of PLP and RLP on prosthesis use for persons with LLA [18]. These researchers found that only PLP predicted nonuse of a prosthesis. However, no studies have investigated the role of perceived effect of prosthesis use (i.e., the belief that the prosthesis aggravates or alleviates pain) on PLP and RLP. Understanding the perceived relationship between a prosthesis and pain may be far more informative than just the presence of pain.

\section{PRESENT STUDY}

Identifying correlates of prosthesis use has the potential to inform prosthetic rehabilitation and advances in prosthetic technology. In light of this and given the limitations in previous research, the primary objectives of the current study were threefold. First, we sought to identify rates of prosthesis use in a diverse and relatively large group of persons with either ULA or LLA representing a wider range of etiologies than has previously been examined. Second, we sought to identify factors related to prosthesis use, including clinical (e.g., etiology) and demographic variables, with particular interest in the effect of PLP and RLP on rates of prosthesis use, as well as the perceived effect of prosthesis use on pain. Finally, in light of the very different functional limitations incurred by persons with ULA and LLA, we wanted to examine the differential rates and predictors of prosthesis use in persons with ULA versus LLA.

\section{METHODS}

\section{Participants}

Potential participants included persons who had undergone a LLA at one of two Seattle-based hospitals (Harborview Medical Center and the Department of Veterans Affairs (VA) Puget Sound Health Care System). These hospitals provided names of potential participants as part of a larger study on pain following LLA [24]. Additional participants were recruited from a list of persons with amputation at a Spokane-based rehabilitation clinic (St. Luke's Rehabilitation Institute). Finally, participants were recruited via an advertisement in inMotion, a national magazine published by the Amputee Coalition of America, and from flyers posted in Seattle-based prosthetist offices as well as other local clinics. Inclusion criteria specified that respondents were to be (1) $\geq 6$ months postamputation, (2) able to read English, and (3) $\geq 18$ years of age. The study protocol was approved by the University of Washington Human Subjects Committee and Institutional Review Board.

A total of 2,127 individuals who had undergone a LLA were mailed questionnaires. Of those mailed, 186 were returned indicating the recipient was deceased, 397 were returned by the postal service as undeliverable, and 247 were returned by ineligible respondents (including those who were $<6$ months postamputation, persons who did not have a limb amputation, or persons $<18$ years of age). Therefore, a total of 1,297 surveys could have been completed and returned. Of those potentially eligible, 46 declined participation, and a total of 752 usable questionnaires 
were returned, resulting in a response rate of 58 percent (752/1,297).

Questionnaires were also mailed to 295 persons who had undergone ULA. Of those mailed, 43 were returned by the postal service as undeliverable, 8 were returned indicating the recipient was deceased, and 18 were ineligible (including those who were $<6$ months postamputation, persons who did not have a limb amputation, or persons $<18$ years of age). Therefore, a total of 226 surveys were potentially eligible for inclusion. Of those, 9 participants declined participation. A total of 107 usable questionnaires were returned, yielding a response rate of 47 percent (107/226).

\section{Measures}

\section{Demographic and Clinical Information}

The survey questionnaire assessed demographic information, including age, sex, marital status, ethnicity, employment status, and education level. The survey assessed relevant clinical information such as level of amputation (including toes, foot, ankle, transtibial, knee disarticulation, transfemoral, hip disarticulation, hemipelvectomy, or "Other" for LLAs and fingers, partial hand, wrist disarticulation, transradial, elbow disarticulation, transhumeral, shoulder, or forequarter for ULAs), time since amputation, and etiology of amputation. Participants were permitted to select multiple reasons for amputation because limb loss may be the result of a series of complicated events. Choices included tumor, diabetes, vascular disease (not diabetes), injury, congenital, infection, gangrene, other, or do not know.

\section{Pain}

Indices of amputation-related pain over the past 3 months, including average PLP and RLP, were assessed on a $0-10$ numeric rating scale (NRS) for pain, with 0 indicating no pain and 10 indicating the worst imaginable pain. Such 0-10 scales have demonstrated their validity and reliability as measures of pain by their strong association with other measures of pain intensity and stability over time [25].

\section{Effect of Prosthesis Use on Pain}

We also assessed the perceived effect of prosthesis use on RLP and PLP (e.g., worsens, makes better, does not affect, and do not know).

\section{Prosthesis Use}

All participants were asked if they used a prosthesis and, if so, for how many hours per day. Persons with ULAs were also asked how many days per month they used their prosthesis.

\section{Procedures}

Participants were recruited from a Spokane-based rehabilitation clinic, two Seattle-based hospitals, and through other recruitment methods (e.g., flyers, magazine advertisement, word of mouth). Surveys were sent to all patients of the Spokane-based rehabilitation clinic as well as a random sample of patients who had undergone amputation at the two Seattle-based hospitals. Interested individuals who learned of the study through flyers and the magazine advertisement were instructed to call the research office for more information. Potential recruits received a packet by mail containing a cover letter, the survey/questionnaire, and a stamped envelope for returning the completed survey/questionnaire. The cover letter accompanying the questionnaire instructed respondents to complete the questionnaire even if they did not experience any pain. To facilitate recruitment, we made followup calls and sent mailings to those who had not returned the packet. Participants were also contacted by a research assistant to obtain or clarify any missing or incomprehensible answers.

\section{Analytic Approach}

We performed descriptive analyses to examine the demographic and clinical profile of persons with ULA versus LLA, as well as rates of use. We conducted T-tests and analyses of variance to examine differences in prosthesis use by amputation site (distal versus proximal), sex, employment status (divided between those with fulltime, part-time, and/or school versus all others), pain severity (grouped by those with a pain rating between 0 6 versus $7-10$ on a $0-10$ NRS), level of education (high school, vocational training, or below versus some college and above), and presence versus absence of PLP and RLP. We calculated Pearson's product moment correlation coefficients to examine the relationships among continuous variables (e.g., age) and hours per day and days per month of prosthesis use.

Differences in prosthesis use were also examined between persons with trauma-related LLA $(n=361)$ versus those with dysvascular-related LLA. We removed participants who endorsed tumors $(4.3 \%)$ or congenital 
issues (3.1\%) as reasons for amputation from these analyses; they constituted a very small percentage of the sample. The rationale for excluding congenital etiologies was that the experience of having an amputation under these circumstances would be markedly different than losing a limb as an adult. For example, we reasoned that the timing and experience of being fitted with a prosthesis would be quite different than for an individual who lost a limb as an adult. We excluded "Other” because we lacked critical information regarding etiology. For example, a participant may check "Other" because he or she had both an injury and an infection. So, we reasoned it would be best not to make guesses about etiology without additional critical information. Finally, we excluded those who marked tumor as an etiology because these participants have less in common medically with our comparison groups (trauma and vascular/infection) and represented a small proportion of our sample. Those who endorsed both dysvascular and trauma as reasons for amputation (5\%) were also excluded from these analyses because they could not be included in any particular category. Participants included in these analyses $(n=537)$ could be more confidently placed in either trauma- or non-traumarelated amputation subgroups. Moreover, we were able to conclude that almost all of our non-trauma-related subset included persons with amputations due to vascular disease, diabetes, or related complications. Because the vast majority of the subjects with upper-limb loss reported trauma-related amputation, we did not attempt to compare trauma versus nontrauma etiologies in this sample.

\section{RESULTS}

\section{Sample Characteristics}

\section{Lower Limb}

The current sample included 752 persons with LLA. A majority of these participants were recruited from the two Seattle-based hospitals: Harborview Medical Center (42.4\%) and the VA Puget Sound Health Care System (20.5\%). About one-fifth of the sample was recruited from the national magazine advertisement in inMotion (21.4\%), and the remaining participants were from the Spokane-based rehabilitation clinic (7.4\%) and flyers or word of mouth (8.3\%). Demographic and amputationrelated descriptive information for the 752 lower-limb loss respondents is presented in Tables 1 and 2, respec- tively. Within this sample, 542 (72.1\%) of the participants were men and 210 (27.9\%) were women. The mean age of participants was 54.36 years (standard deviation [SD] = 14.62; range $=19-92$ ). The majority of the sample was Caucasian (88.0\%) and had some college education or greater (58.5\%). Transtibial amputations were more common than any other level (56.1\%) for LLA, followed by transfemoral amputations (30.1\%). Injury was the most commonly endorsed reason for amputation (53.5\%), followed by infection (23.4\%), vascular disease (22.3\%), and gangrene (20.9\%). Approximately 13 percent endorsed "Other" as the cause for amputation. A wide degree of variability was found in the number of years since amputation (mean $\pm \mathrm{SD}=12.52 \pm 14.54$, range $=0.08-73.50)$ (Tables 1-2).

\section{Upper Limb}

The sample of persons with ULA consisted of 107 respondents recruited mainly from the Harborview Medical Center (78.5\%), with a much smaller percentage of persons from the VA Puget Sound Health Care System (3.7\%) and the remainder from the national advertisement in inMotion (4.7\%) and the Spokane-based rehabilitation clinic (13.1\%). Demographic and amputationrelated descriptive information for the 107 upper-limb loss respondents is presented in Tables 1 and 2, respectively. Within this sample, 77 (72.0\%) of the participants were men and 30 (28.0\%) were women. The mean \pm SD age of participants was $46.9 \pm 14.50$ (range $=18-84$ ) at the time of study participation. Analogous to the lowerlimb loss sample, the majority of the sample was Caucasian (88.8\%) and had some college education or greater (55.1\%). Transhumeral amputations were more common than any other level (38.3\%), followed by transradial amputations (30.8\%). Injury was the most commonly endorsed reason for amputation (83.2\%), followed by "Other" (15.9\%), infection (8.4\%), gangrene (7.5\%), and vascular disease (3.7\%). A wide degree of variability was noted in the number of years since amputation (mean \pm $\mathrm{SD}=10.88 \pm 12.06$, range $=0.17-60.33)$ (Tables 1-2) .

\section{Prosthesis Use}

Approximately 84 percent of persons with LLA and 56 percent of persons with ULA reported using a prosthesis for a mean \pm SD of $12.47 \pm 4.34$ and $10.67 \pm 5.00$ hours per day, respectively. Participants with ULA reported wearing a prosthesis for a mean \pm SD of $24.45 \pm 8.5$ days per month (range $=1-31$ ). Chi-square analysis revealed 
Table 1.

Demographic characteristics of persons with lower-limb $(n=752)$ versus upper-limb $(n=107)$ amputation.

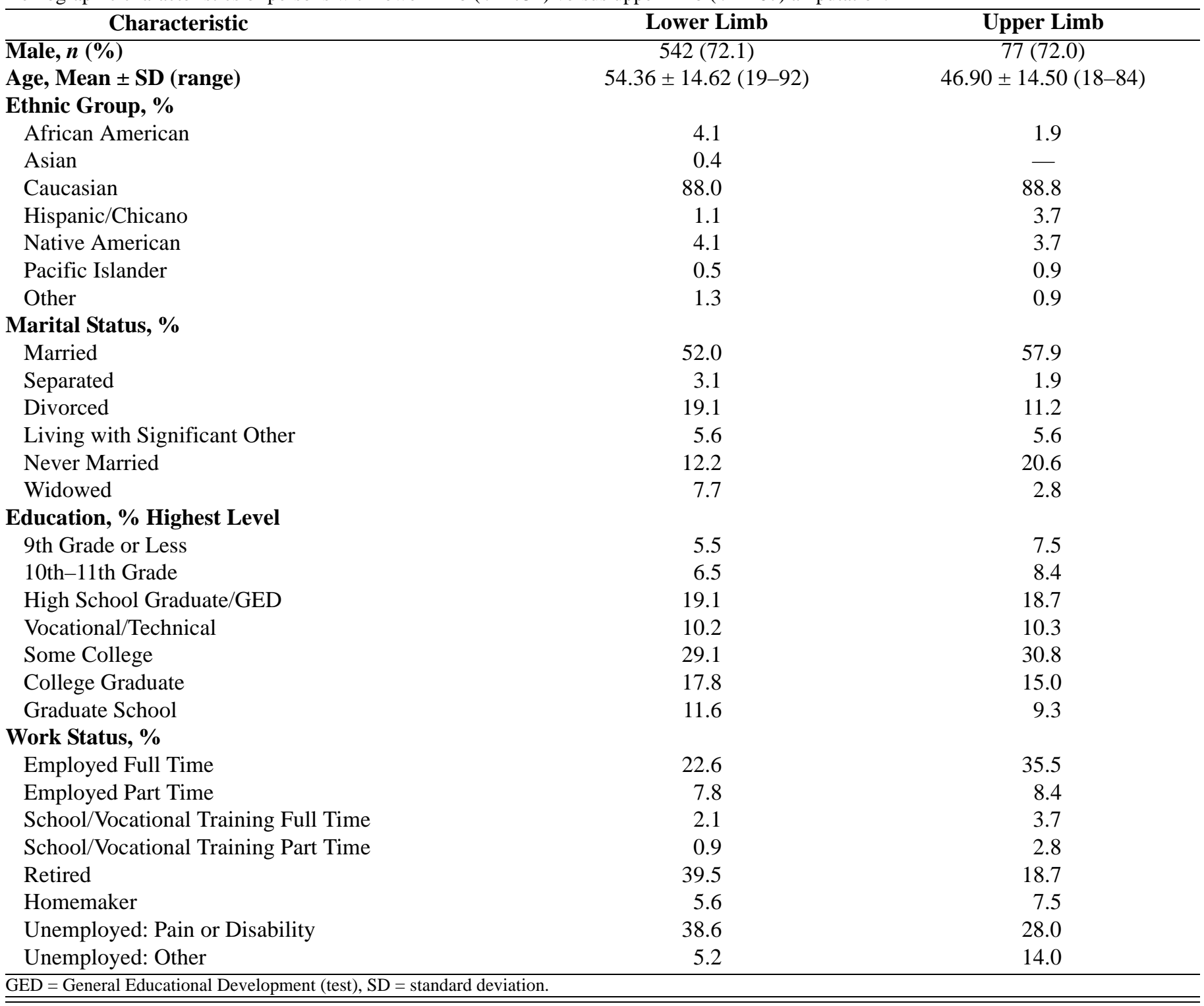

that participants with LLA were significantly more likely to wear a prosthesis than participants with ULA $\left(\chi^{2}=\right.$ 46.13, $p<0.001$ ) (Table 2).

\section{Lower Limb}

For participants with LLA, greater prosthesis use (more hours per day) was associated with full-time or part-time employment or schooling versus all else, $t_{(624)}=$ $5.88, p<0.01$; being married/living with a partner, $t_{(581)}=$ 2.15, $p<0.05$; distal amputations (defined as transtibial, ankle, foot, and toe amputations), $t_{(624)}=-6.24, p<0.01$; and trauma-related amputations, $t_{(537)}=-3.30, p<0.01$.
Results of bivariate correlation analyses revealed an inverse relationship between age and prosthesis use ( $r=$ $-0.12, p<0.05$ ). Level of education, sex, and proximal amputations were not associated with prosthesis use for participants with LLA (Table 3).

\section{Upper Limb}

For persons with ULA, greater prosthesis use (more hours per day) was significantly associated with proximal amputations (defined as elbow disarticulation, transhumeral, shoulder disarticulation, and scapulothoracic amputations), $t_{(58)}=-2.45, p<0.05$ (Table 4). Greater prosthesis use 
JRRD, Volume 45, Number 7, 2008

Table 2.

Clinical characteristics of persons with lower-limb $(n=752)$ versus upper-limb $(n=107)$ amputation.

\begin{tabular}{|c|c|c|}
\hline Characteristic & Lower Limb & Upper Limb \\
\hline \multicolumn{3}{|l|}{ Amputation Etiology, \% } \\
\hline Tumor & 4.3 & 0.9 \\
\hline Vascular Disease, Not Diabetes & 22.3 & 3.7 \\
\hline Injury & 53.5 & 83.2 \\
\hline Congenital & 3.1 & 0.9 \\
\hline Gangrene & 20.9 & 7.5 \\
\hline Other & 13.4 & 15.9 \\
\hline Do Not Know & - & 0.9 \\
\hline Yr Since Amputation, Mean \pm SD (range) & $12.52 \pm 14.54(0.08-73.50)$ & $10.88 \pm 12.06(0.17-60.33)$ \\
\hline \multicolumn{3}{|l|}{ Location of Amputation: Lower Limb, \% } \\
\hline Transtibial & 56.1 & - \\
\hline Knee Disarticulation & 4.1 & - \\
\hline Transfemoral & 30.1 & - \\
\hline Hip Disarticulation & 2.3 & - \\
\hline Hemipelvectomy & 0.4 & - \\
\hline Other & 0.4 & - \\
\hline \multicolumn{3}{|l|}{ Prosthesis Use, \% } \\
\hline Yes $^{*}$ & 83.9 & 56.1 \\
\hline $\mathrm{No}^{*}$ & 16.1 & 43.9 \\
\hline If Yes: Hours/Day, Mean \pm SD (range) ${ }^{\dagger}$ & $12.47 \pm 4.34(0-24)$ & $10.67 \pm 5.00(1-24)$ \\
\hline Elbow Disarticulation & - & 1.9 \\
\hline Transhumeral & - & 38.3 \\
\hline Shoulder Disarticulation & - & 2.8 \\
\hline Forequarter & - & 1.9 \\
\hline \multicolumn{3}{|l|}{ Pain in Past 3 Months (NRS 0-10), Mean \pm SD } \\
\hline Phantom Limb Pain & $4.80 \pm 2.53$ & $4.98 \pm 2.77$ \\
\hline Residual Limb Pain & $4.66 \pm 2.71$ & $4.71 \pm 2.77$ \\
\hline \multicolumn{3}{|c|}{$\begin{array}{l}{ }^{*} \text { Participants with lower-limb amputation (LLA) were significantly more likely to wear prosthesis than those with upper-limb a } \\
0.001) \text {. } \\
{ }^{\dagger} \text { Participants with LLA wore their prostheses significantly more hours per day than those with ULA, } F_{(1,684)}=9.25, p<0.01 \text {. } \\
\text { NRS = numeric rating scale, SD = standard deviation. }\end{array}$} \\
\hline
\end{tabular}

(more days per month) was associated with distal amputations (defined as partial hand, wrist disarticulation, and transradial amputations), $t_{(58)}=-3.72, p<0.05$, as well as being married/living with a partner, $t_{(58)}=-2.09, p<0.05$ 
Table 3.

Demographic and amputation-related characteristics and hours per day of prosthetic use for persons with lower-limb amputation $(n=752)$.

\begin{tabular}{|c|c|c|c|c|}
\hline Variable & $n$ & $\begin{array}{l}\text { Mean } \pm \text { SD } \\
\text { (Hours/Day) }\end{array}$ & $t$ & $d f$ \\
\hline \multicolumn{5}{|l|}{ Education } \\
\hline Vocational/High School and Below & 258 & $12.14 \pm 4.51$ & -1.65 & 623 \\
\hline Some College and Above & 367 & $12.72 \pm 4.20$ & & \\
\hline \multicolumn{5}{|l|}{ Employment } \\
\hline Full Time, Part Time, School & 189 & $13.98 \pm 3.67$ & $5.88^{*}$ & 624 \\
\hline Male & 462 & $12.43 \pm 4.40$ & -0.40 & 624 \\
\hline Female & 164 & $12.59 \pm 4.20$ & & \\
\hline \multicolumn{5}{|l|}{ Married/Living with Partner } \\
\hline Yes & 382 & $12.83 \pm 4.09$ & $2.15^{\dagger}$ & 581 \\
\hline No & 201 & $12.03 \pm 4.64$ & & \\
\hline \multicolumn{5}{|l|}{ Etiology of Amputation } \\
\hline Traumatic & - & $13.02 \pm 4.16$ & $-3.30^{*}$ & 537 \\
\hline Nontraumatic $\S$ & - & $11.79 \pm 4.38$ & & \\
\hline \multicolumn{5}{|c|}{ 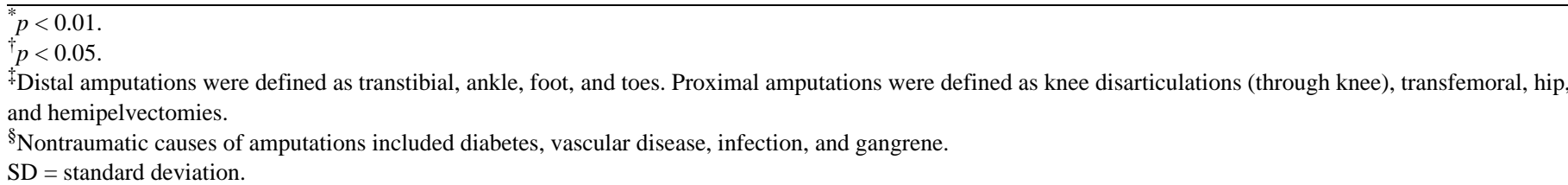 } \\
\hline
\end{tabular}

Table 4.

Demographic and amputation-related characteristics and hours per day of prosthesis use for persons with upper-limb amputation ( $n=107)$.

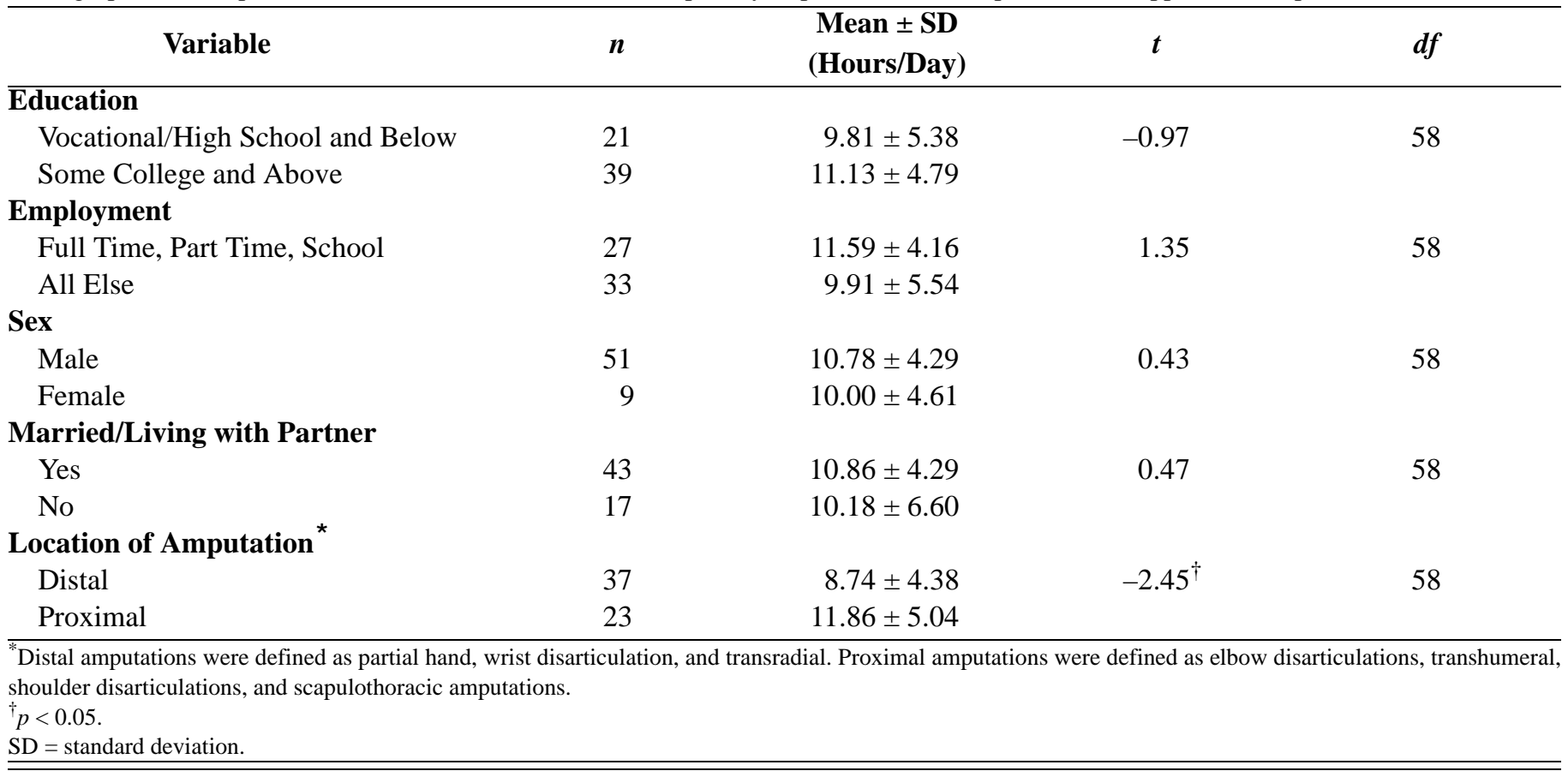


(Table 5). Etiology, level of education, employment status, and sex were not associated with prosthesis use for participants with ULA.

\section{Pain Intensity and Prosthesis Use}

\section{Lower Limb}

Greater prosthesis use (more hours per day) was significantly associated with a reported absence of PLP, $t_{(624)}=-2.30, p<0.001$, for participants with LLA. No difference in use related to reported presence of RLP was found. Participants who reported that prosthesis use "Worsens PLP" described significantly less prosthesis use (hours per day) than participants who reported that the use of a prosthesis “Does Not Affect PLP," $F_{(3,452)}=$ 4.51, $p<0.05$. Participants who reported that prosthesis use "Worsens PLP" reported significantly greater PLP intensity than those who reported that prosthesis use "Makes PLP" better, $F_{(3,543)}=2.88, p<0.05$. Those who reported that prosthesis use contributes to RLP reported wearing a prosthesis for a significantly greater number of hours per day than those who reported that prosthesis use does not affect RLP, $t_{(473)}=3.23, p<0.01$ (Table 6).

\section{Upper Limb}

Prosthesis use (both in terms of hours per day and days per month) was unrelated to the perception that prosthesis use affects pain (for both PLP and RLP). Pros- thesis use was also unrelated to reported RLP for this group (all $p$-values $>0.10$ ). Although prosthesis use was unrelated to the reported presence or absence of PLP, a significant relationship between PLP intensity and prosthesis use did emerge. Specifically, persons who reported average PLP intensity of 6 on the NRS for pain (0-10) wore their prostheses for significantly more hours per day than those who reported greater pain intensity, $t_{(45)}=$ $-2.31, p<0.05$. Prosthesis use was not related to reported PLP or RLP severity (Table 7).

\section{DISCUSSION}

Prior research examining prosthesis use has been limited by a number of factors. Previous studies have focused primarily on persons with LLA, leading to an overrepresentation of elderly persons with amputations secondary to vascular problems. Researchers have also typically examined persons with either LLA or ULA or have collapsed both into one sample without comparing differential rates of use between these two groups in the interest of considering the unique functional needs of each. In turn, clear predictors of prosthesis use by amputation site (i.e., upper vs lower limb) have not been identified. Finally, a paucity of research exists examining the effect of PLP and RLP on prosthesis use, both in terms of the effect of pain intensity on prosthesis use and the

Table 5.

Demographic and amputation-related characteristics and days per month of prosthesis use for persons with upper-limb amputation ( $n=107)$.

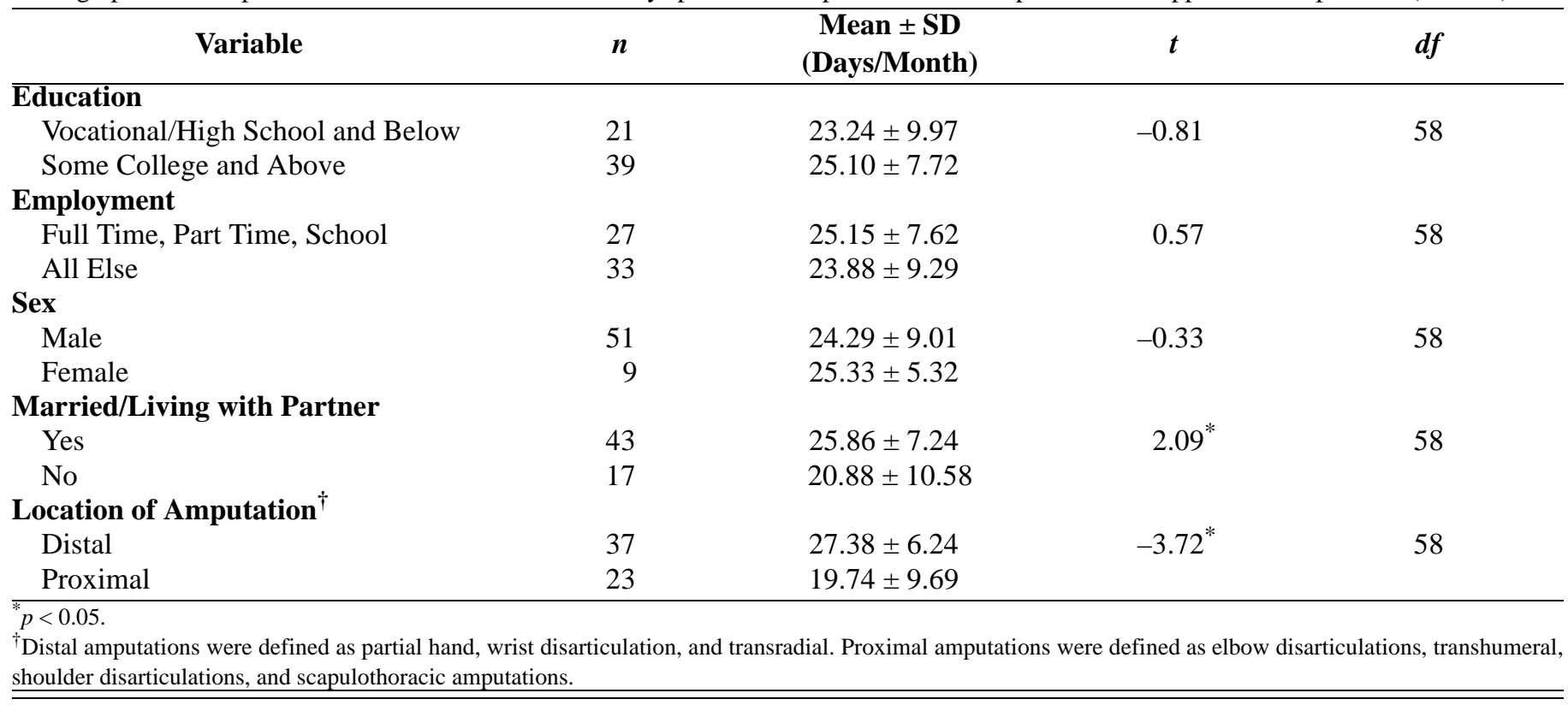


Table 6.

Average pain intensity in past 3 months and prosthesis use for persons with lower-limb amputation $(n=752)$.

\begin{tabular}{|c|c|c|c|}
\hline Variable & $n$ (Valid \%) & $\begin{array}{l}\text { Prosthesis Use, } \\
\text { Hours/Day (n) }\end{array}$ & $\begin{array}{c}\text { Pain Intensity, } \\
\text { 0-10 NRS (n) }\end{array}$ \\
\hline \multicolumn{4}{|c|}{ Effect of Prosthesis on PLP } \\
\hline Worsens PLP & $115(21.1)$ & $11.06(111)^{*}$ & $5.28(115)^{\dagger}$ \\
\hline Does Not Affect PLP & $273(50.1)$ & $12.76(254)^{*}$ & 4.67 (273) \\
\hline Do Not Know & $70(12.8)$ & $7.50(2)$ & 4.99 (69) \\
\hline No & - & $11.83(275)^{\ddagger}$ & $4.76(282)$ \\
\hline \multicolumn{4}{|l|}{ Do You Have PLP? } \\
\hline Yes & - & $12.23(458)^{\S}$ & - \\
\hline No & - & $13.13(168)^{\S}$ & - \\
\hline \multicolumn{4}{|l|}{ Intensity of PLP Pain } \\
\hline 6 & - & $12.16(350)$ & - \\
\hline No & - & $12.84(150)$ & - \\
\hline \multicolumn{4}{|l|}{ Intensity of RLP Pain } \\
\hline 6 & - & 12.38 (359) & - \\
\hline 7 & - & $12.28(117)$ & - \\
\hline \multicolumn{4}{|c|}{ 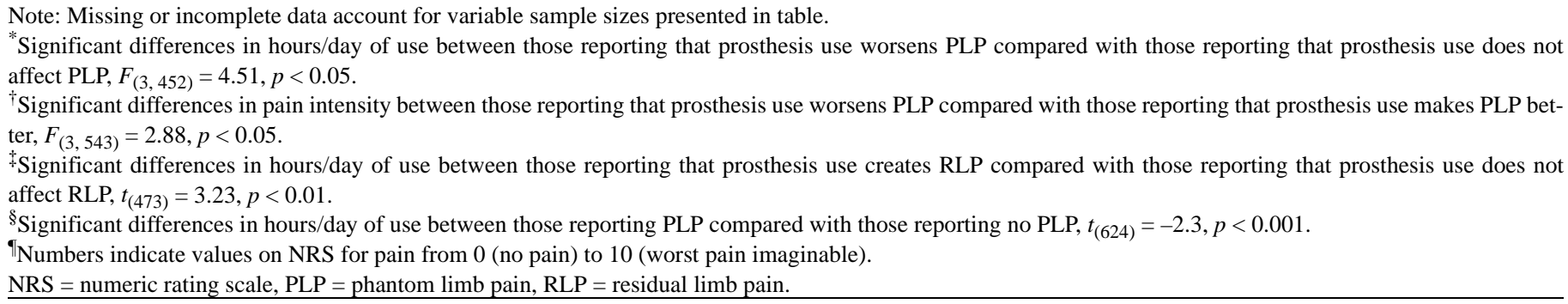 } \\
\hline
\end{tabular}

perceived effect of prosthesis use on pain. The current study attempted to address these limitations by examining prosthesis use in a large and diverse sample. We also hoped to add to the literature by comparing those with ULA versus LLA and by representing multiple etiologies.

\section{Rates of Prosthesis Use}

Our results indicate that $\sim 84$ percent of participants with LLA reportedly wear a prosthesis for an average of 12.47 hours per day. The average hours per day of use is commensurate with the few studies examining persons with LLA, which found that prosthesis use ranges from approximately 10.0 to 11.5 hours per day $[13,16]$. For individuals with ULA, use rates were considerably lower, with approximately 56 percent of persons in our sample reporting prosthesis use for an average of $\sim 11.0$ hours per day and 24.0 days per month. These rates are slightly below those reported in previous research (e.g., from $60 \%$ $89 \%)[2,4,19,26]$.
Regarding etiology of amputation, our data demonstrated no significant difference in hours per day of use in those with a lower-limb traumatic etiology versus all others with a LLA (13.02 vs 11.79 hours per day, respectively). This finding is inconsistent with previous studies reporting variable rates of use by etiology, ranging from 6 hours per day for persons with vascular amputations [15] to more than 10 hours per day for persons with traumatic amputations [8]. Although differences in study protocol and sampling may in part explain these findings, this inconsistency calls for further examination of the role of etiology in prosthesis use.

\section{ULA Versus LLA and Prosthesis Use}

In comparing those with ULA versus LLA, we noticed a number of important differences. Most notably, participants with LLA were significantly more likely to wear a prosthesis and to wear a prosthesis for a greater number 
JRRD, Volume 45, Number 7, 2008

Table 7.

Average pain intensity in past 3 months and prosthesis use for persons with upper-limb amputation $(n=107)$.

\begin{tabular}{|c|c|c|c|c|}
\hline \multirow{2}{*}{ Variable } & \multirow{2}{*}{$n$ (Valid \%) } & \multicolumn{2}{|c|}{ Prosthesis Use } & \multirow{2}{*}{$\begin{array}{c}\text { Pain Intensity, } \\
\text { 0-10 NRS (n) }\end{array}$} \\
\hline & & Hours/Day (n) & Days/Month (n) & \\
\hline \multicolumn{5}{|c|}{ Effect of Prosthesis on PLP } \\
\hline Worsens PLP & $22(25.6)$ & $9.69(16)$ & $21.5(16)$ & $4.86(22)$ \\
\hline Makes PLP Better & $10(11.6)$ & $10.80(10)$ & $26.3(10)$ & $5.80(10)$ \\
\hline Does Not Affect PLP & $26(30.2)$ & $11.28(25)$ & $25.7(25)$ & $4.38(26)$ \\
\hline Do Not Know & $28(32.6)$ & $10.52(1)$ & $8.0(1)$ & $5.32(28)$ \\
\hline No & - & $10.31(35)$ & $8.29(35)$ & $4.45(38)$ \\
\hline Do Not Know & - & $0(0)$ & $0(0)$ & $5.08(24)$ \\
\hline \multicolumn{5}{|l|}{ Do You Have PLP? } \\
\hline Yes & - & $10.52(52)$ & $24.19(52)$ & - \\
\hline No & - & $11.63(8)$ & $26.13(8)$ & - \\
\hline \multicolumn{5}{|l|}{ Do You Have RLP? } \\
\hline Yes & - & $10.50(48)$ & $24.10(48)$ & - \\
\hline No & - & $11.33(12)$ & $25.83(12)$ & - \\
\hline \multicolumn{5}{|l|}{ Intensity of RLP Pain* } \\
\hline 6 & - & $10.94(35)$ & $24.46(35)$ & - \\
\hline 7 & - & $9.78(9)$ & $23.56(9)$ & - \\
\hline
\end{tabular}

of hours per day than were persons with ULA. Further, demographic and medical predictors of prosthesis use varied by amputation site (i.e., upper or lower limb). In particular, factors related to greater use (in hours per day) in persons with LLA included being younger, being employed, being married, having a distal amputation, and having an amputation of traumatic etiology. By contrast, level of amputation was the only variable associated with prosthesis use for persons with ULA. Specifically, those with a distal amputation wore their prostheses for significantly more days per month than those with a proximal amputation.

These differences highlight the potentially unique needs of these two amputee populations and further emphasize the need to explore reasons for these differences. For example, LLAs may present more challenging functional limitations, which are reflected in the greater use of a prosthesis overall. This possibility is supported by our finding that among persons with LLA, employment or active schooling (as opposed to retirement or dis- ability) was associated with greater prosthesis use. In contrast, prosthesis use was unrelated to employment status for persons with upper-limb loss. However, greater prosthesis use was related to distal amputations for both ULA and LLA. This finding may reflect greater functional limitations in using prostheses that serve to accommodate proximal versus distal amputations.

As previously stated, the research to date is both equivocal and sparse, with inconsistencies regarding the effects of demographic and clinical variables on prosthesis use. Other factors not included in the current study may eclipse the importance of various demographic and clinical characteristics that we measured. For example, given that prosthetic legs more closely approximate the function of the lost limb, whereas prosthetic arms do not as closely approximate the function of the lost limb, cosmesis may be a more important factor in the decision to wear a prosthetic for those with upper-limb loss. This speculation is supported by earlier research that found that appearance of the prosthesis was comparable in importance to its function for those with upper-limb loss 
[19] and that the majority of these individuals report wearing a prosthesis for cosmetic reasons $[17,23]$. It was outside the scope of the current study to include all possible variables related to prosthesis use, but numerous factors worth exploring in future research remain.

\section{Pain and Prosthesis Use}

The results of the current study also confirm the importance of considering the effect of PLP and RLP on prosthesis use, which is reflected in the differential effect of pain for persons with ULA versus LLA. For persons with LLA, the perceived effect of the prosthesis on PLP and RLP may significantly affect prosthesis use, since participants who reported that prosthesis use worsens PLP (versus those who reported that prosthesis use did not effect PLP) wear their prosthesis for significantly fewer hours per day. Notably, these two groups did not differ on reported PLP intensity. The fact that no difference was noted in reported pain intensity speaks to the importance of examining the perceived effect of prosthesis use on PLP or RLP, as opposed to an assessment of pain intensity. Moreover, persons with LLA who reported PLP wore their prostheses for significantly fewer hours per day than those who denied having PLP. Finally, those who reported RLP wore their prostheses for a significantly greater number of hours per day than those who denied RLP. In contrast, pain did not significantly affect prosthesis use for persons with ULA. Again, the extent to which PLP and RLP affect prosthesis use - which may be eclipsed by other factors, such as cosmesis-is unknown and is an important area for further investigation.

\section{Limitations}

Several limitations are worth noting in the present study. Although we made efforts to reach as many people with limb loss as possible and the demographic characteristics in the current study were similar to previous studies, we cannot know if the samples described here are representative of the population of individuals living with an amputation. As with all survey research, the characteristics of individuals who participate may differ from the general population. Because at least 78.6 percent of the sample was recruited from Pacific Northwest healthcare resources, the sample is likely most representative of that area of the United States, although a portion of the sample was recruited through a national source. Finally, the correlational nature of this study also precludes conclusions concerning the causality of relationships between variables (e.g., the effect of PLP on prosthesis use).
Regarding etiology, respondents were able to report more than one cause of amputation to reflect the complex pathways leading to limb loss. However, this method made it more difficult to categorize respondents into subgroups based on etiology. When comparing traumarelated versus dysvascular amputation, we had to exclude participants who reported both injury and vascular disease/diabetes as causes of amputation. In addition, it is possible that for some participants, vascular issues or diabetes could have left them more susceptible to limb loss (instead of limb repair) after an injury.

Finally, the scope of the current study did not include other potentially relevant variables that may significantly affect prosthesis use. Future studies may examine the effect of psychological health on prosthesis use, because untreated mental health issues may directly or indirectly affect prosthesis use. Future research may also include an assessment of different types of prosthetic devices and the effect of the goodness of prosthetic fit. In light of varying levels of access to healthcare, one may assess the effect of the duration and quality of postamputation rehabilitiation methods on prosthesis use as well.

\section{CONCLUSIONS}

Limitations of the current study notwithstanding, these results underscore the importance of examining factors related to prosthesis use and the differential effect that these variables may have when the etiology and location of amputation are considered. We believe that this study also highlights the importance of examining both incidence and prevalence amputation data.

In terms of future work, more research is needed regarding resource allocation and appropriate interventions for subgroups of individuals living with limb loss. Also, given that PLP is a common experience after amputation, understanding the effect of this variable on prosthesis use is imperative. Further work in this area could assess the relationship between PLP and prosthesis use in a longitudinal design. Finally, these results should be replicated in a more ethnically, economically, and educationally diverse sample to improve generalizability.

\section{ACKNOWLEDGMENTS}

This material was based on work supported by the National Institutes of Health, National Institute of Child 
Health and Human Development, National Center for Medical Rehabilitation Research (grant P01 HD33988).

The authors have declared that no competing interests exist.

\section{REFERENCES}

1. Dillingham TR, Pezzin LE, MacKenzie EJ. Limb amputation and limb deficiency: Epidemiology and recent trends in the United States. South Med J. 2002;95(8):875-83. [PMID: 12190225]

2. Millstein S, Bain D, Hunter GA. A review of employment patterns of industrial amputees-Factors influencing rehabilitation. Prosthet Orthot Int. 1985;9(2):69-78. [PMID: 4047922]

3. Sheikh K. Return to work following limb injuries. J Soc Occup Med. 1985;35(4):114-17. [PMID: 4079344]

4. Wright TW, Hagen AD, Wood MB. Prosthetic usage in major upper extremity amputations. J Hand Surg [Am]. 1995; 20(4):619-22. [PMID: 7594289]

5. Davidson J. A survey of the satisfaction of upper limb amputees with their prostheses, their lifestyles, and their abilities. J Hand Ther. 2002;15(1):62-70. [PMID: 11866354

6. Schoppen T, Boonstra A, Groothoff JW, De Vries J, Göeken LN, Eisma WH. Physical, mental, and social predictors of functional outcome in unilateral lower-limb amputees. Arch Phys Med Rehabil. 2003;84(6):803-11. [PMID: 12808530]

7. Pezzin LE, Dillingham TR, MacKenzie EJ, Ephraim P, Rossbach P. Use and satisfaction with prosthetic limb devices and related services. Arch Phys Med Rehabil. 2004; 85(5):723-29. [PMID: 15129395]

8. Dillingham TR, Pezzin LE, MacKenzie EJ, Burgess AR. Use and satisfaction with prosthetic devices among persons with trauma-related amputations: A long-term outcome study. Am J Phys Med Rehabil. 2001;80(8):563-71. [PMID: 11475475]

9. Burger H, Marincek C, Isakov E. Mobility of persons after traumatic lower limb amputation. Disabil Rehabil. 1997;19(7): 272-77. [PMID: 9246543]

10. Smith DG, Horn P, Malchow D, Boone DA, Reiber GE, Hansen ST Jr. Prosthetic history, prosthetic charges, and functional outcome of the isolated, traumatic below-knee amputee. J Trauma. 1995;38(1):44-47. [PMID: 7745656]

11. Beekman CE, Axtell LA. Prosthetic use in elderly patients with dysvascular above-knee and through-knee amputations. Phys Ther. 1987;67(10):1510-16. [PMID: 3659135]

12. Wong MW. Lower extremity amputation in Hong Kong. Hong Kong Med J. 2005;11(3):147-52. [PMID: 15951578]

13. Gauthier-Gagnon C, Grise MC, Potvin D. Predisposing factors related to prosthetic use by people with a transtibial and transfemoral amputation. J Prosthet Orthot. 1998;10(4): 99-109.

14. Nielson CC, Psonak RA, Kalter TL. Factors affecting the use of prosthetic services. J Prosthet Orthot. 1989;4(1):242-49.

15. Bilodeau S, Hébert R, Desrosiers J. Lower limb prosthesis utilisation by elderly amputees. Prosthet Orthot Int. 2000; 24(2):126-32. [PMID: 11061199]

16. Pohjolainen T, Alaranta H, Kärkkäinen M. Prosthetic use and functional and social outcome following major lower limb amputation. Prosthet Orthot Int. 1990;14(2):75-79. [PMID: 2235304]

17. Burger H, Marincek C. Upper limb prosthetic use in Slovenia. Prosthet Orthot Int. 1994;18(1):25-33. [PMID: 8084746]

18. Dolezal JM, Vernick SH, Khan N, Lutz D, Tyndall C. Factors associated with use and nonuse of an AK prosthesis in a rural, southern, geriatric population. Int J Rehabil Health. 1998;4(4):245-52.

19. Hyberd PJ, Beard DJ, Davey JJ, Morrison JD. A survey of upper-limb prosthesis users in Oxfordshire. J Prosthet Orthot. 1998;10(4):85-91.

20. Roeschlein RA, Domholdt E. Factors related to successful upper extremity prosthetic use. Prosthet Orthot Int. 1989; 13(1):14-18. [PMID: 2717379]

21. Smith DG, Ehde DM, Legro MW, Reiber GE, Del Aguila M, Boone DA. Phantom limb, residual limb, and back pain after lower extremity amputations. Clin Orthop Relat Res. 1999;(361):29-38. [PMID: 10212593]

22. Kooijman CM, Dijkstra PU, Geertzen JH, Elzinga A, Van der Schans CP. Phantom pain and phantom sensations in upper limb amputees: An epidemiological study. Pain. 2000; 87(1):33-41. [PMID: 10863043]

23. Dudkiewicz I, Gabrielov R, Seiv-Ner I, Zelig G, Heim M. Evaluation of prosthetic usage in upper limb amputees. Disabil Rehabil. 2004;26(1):60-63. [PMID: 14660200]

24. Ehde DM, Czerniecki JM, Smith DG, Campbell KM, Edwards WT, Jensen MP, Robinson LR. Chronic phantom sensations, phantom pain, residual limb pain, and other regional pain after lower limb amputation. Arch Phys Med Rehabil. 2000;81(8):1039-44. [PMID: 10943752]

25. Jensen MP, Turner JA, Romano JM, Fisher LD. Comparative reliability and validity of chronic pain intensity measures. Pain. 1999;83(2):157-62. [PMID: 10534586]

26. Kejlaa GH. Consumer concerns and the functional value of prostheses to upper limb amputees. Prosthet Orthot Int. 1993;17(3):157-63. [PMID: 8134275$]$

Submitted for publication September 20, 2007. Accepted in revised form May 14, 2008. 